\title{
Research on Dynamic Characterization of Permanent Magnet Contactor Based on Fuzzy Control
}

\author{
Hailiang $\mathrm{Ji}^{1, \mathrm{a}}$, Changchun $\mathrm{Chi}^{1, \mathrm{~b}}$, Hongsong $\mathrm{Liu}^{1, \mathrm{c}}$ and Huaying $\mathrm{Li}^{1, \mathrm{~d}}$ \\ ${ }^{1}$ College of Electrical Engineering, Shanghai Dianji University, Shanghai, China \\ ajihailiang2011@163.com, bchicc@sdju.edu.cn, '850796567@qq.com, d571269237@qq.com
}

Keywords: Permanent magnet contactor; Fuzzy control; Dynamic characterization; Movable core

\begin{abstract}
This paper presents an optimization method for the dynamic characteristics of permanent magnet (PM) contactor based on fuzzy control. Firstly, The Dynamic characterization of PM contactor is analyzed. Secondly, fuzzy control model is established based on MATLAB. Finally, it is proved that this control method is feasible and effective. The simulation results show that the fuzzy control method can effectively optimize the dynamic characteristics of PM contactor.
\end{abstract}

\section{Introduction}

Compared with the traditional electromagnetic contactor, the PM contactor has the salient merits include energy saving and noise free $[1,2]$. The research on the dynamic characteristics of the PM contactor has important theoretical and practical significance to improve the service life of PM contactor [3, 4].

For the dynamic characteristics of PM contactor, mainly focus on virtual prototyping technology [5-8], structure optimization [9, 10], and intelligent control [11-14]. Due to the structure between PM contactor and electromagnetic contactor is not the same, so many control methods cannot be used in PM contactor. This paper proposes a pulse width modulation (PWM) control method of PM contactor based on fuzzy control. The attraction and the reaction force of the PM contactor can achieve good coordination. And this control system reduces the velocity of the movable core and the energy of contacts impact.

\section{Fuzzy Control System}

Dynamic Mathematic Model. Before the moving contacts touches the static contacts, the mechanical movement equation of the movable core can be written as

$$
F_{\text {mag }}+G-F_{S}=m \frac{d^{2} X}{d t^{2}}
$$

(In the Eq. $1, F_{\operatorname{mag}}$ is the electromagnetic force, $G$ is the gravity of movable core, $F_{S}$ is the spring anti-force, and $m$ is the mass of the movable core.)

According to the Eq. 1, the dynamic model of movable core in MATLAB can be built as shown in Fig. 1.

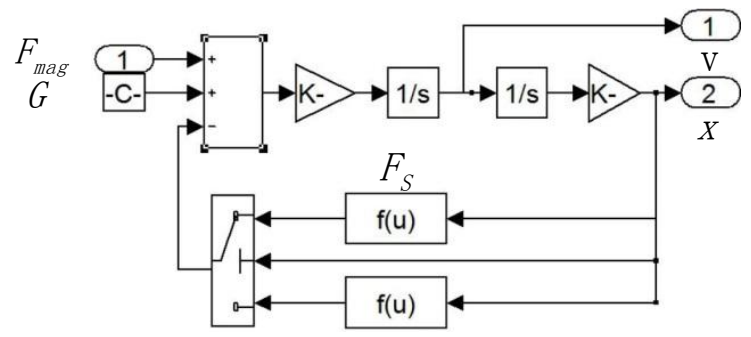

Figure 1. The dynamic model of movable core 
By using finite-element analysis, the nonlinear relationship among the displacement $x$, the electromagnetic force $F_{m a g}$, and the coil current $i$ can be calculated. Though the linear table lookup interpolation, the value of electromagnetic force is introduced into the dynamic simulation model.

Design Fuzzy Controller. A fuzzy controller is built in this work. In the work presented, the inputs are the instantaneous value of the position and the velocity of the movable core, and the output is the PWM duty cycle $D$. For the input and output variables used, three triangular fuzzy sets are built as Fig. 2 shows. The base rules for these three variables are defined in Table 1.

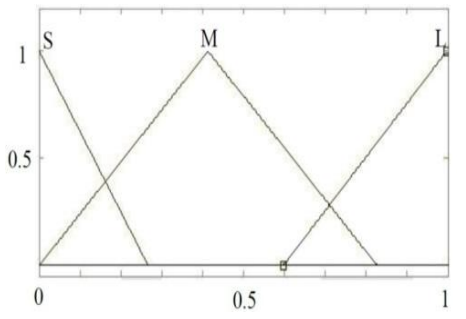

(a) The input variable of $x$

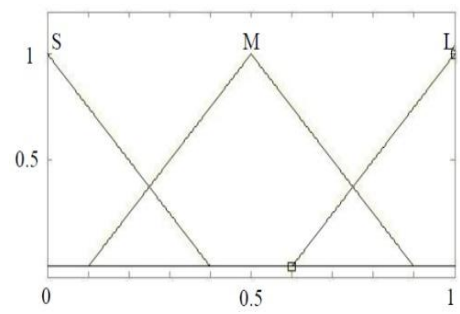

(b) The input variable of $v$

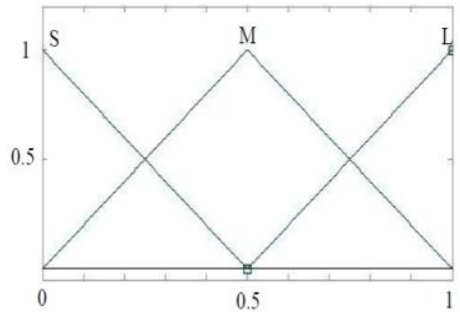

(c) The output value of $D$

Figure 2. Fuzzy sets for input/output variables

Table 1 Fuzzy base rules

\begin{tabular}{|c|c|c|c|c|}
\hline If $(x$ is small $)$ & and & $(v$ is small $)$ & then & $(D$ is large $)$ \\
\hline If $(x$ is small $)$ & and & $(v$ is middle $)$ & then & $(D$ is large $)$ \\
\hline If $(x$ is small $)$ & and & $(v$ is large $)$ & then & $(D$ is middle $)$ \\
\hline If $(x$ is middle $)$ & and & $(v$ is small $)$ & then & $(D$ is large $)$ \\
\hline If $(x$ is middle $)$ & and & $(v$ is middle $)$ & then & $(D$ is middle $)$ \\
\hline If $(x$ is middle $)$ & and & $(v$ is large $)$ & then & $(D$ is small $)$ \\
\hline If $(x$ is large $)$ & and & $(v$ is small $)$ & then & $(D$ is middle $)$ \\
\hline If $(x$ is large $)$ & and & $(v$ is middle $)$ & then & $(D$ is small $)$ \\
\hline If $(x$ is large $)$ & and & $(v$ is large $)$ & then & $(D$ is small $)$ \\
\hline
\end{tabular}

The fuzzy control reasoning process is based on the Mamdani algorithm. The defuzzification process to attain a quantifiable value for the output $D$ is based on max-min algorithm as Fig. 3 shows.

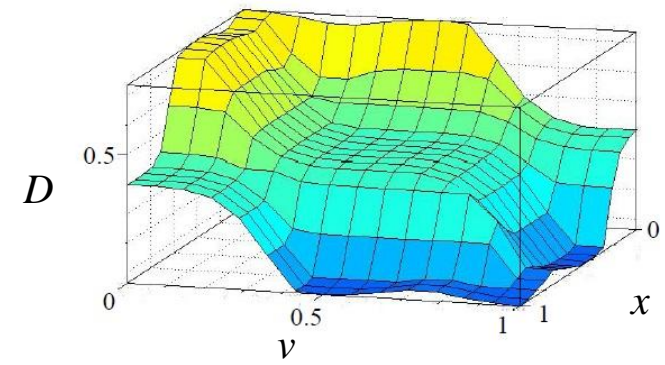

Figure 3. The corresponding relationship between $x, v$ and the $D$

Control System Simulation Model. The output variable value $D$ is divided into 5 equal parts. And the intermediate value as the output. For example, if $D$ is in the $[0,0.2]$ to take 0.1 . The PWM cycle is 2ms. Control system simulation model in MATLAB is built as shown in Fig. 4. 


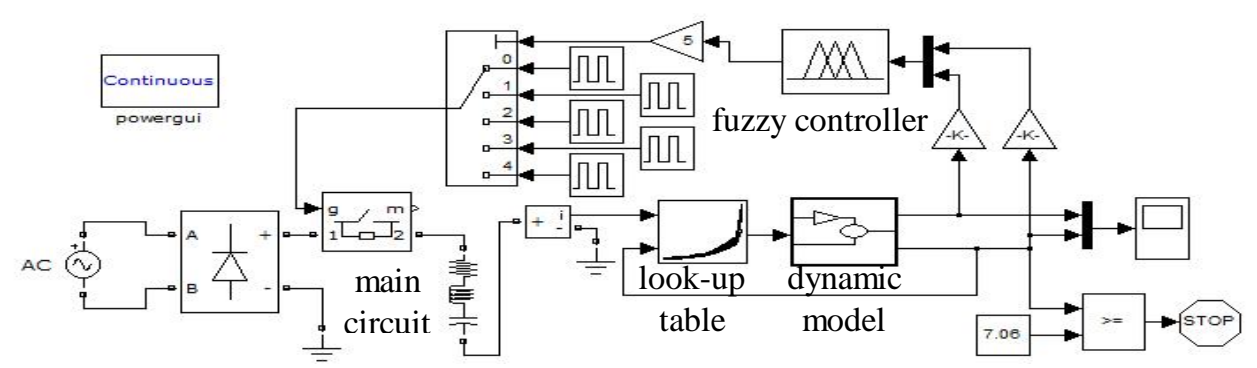

Figure 4. Control system simulation model

\section{Simulation Analysis}

The dynamic simulation is set up in MATLAB. The output duty cycle $D$ by the fuzzy controller to achieve the purpose of regulating the current of the coil. No fuzzy control and fuzzy control are compared in the Fig. 5. Fig. 6 shows that the relationship between the PWM and the coil current.

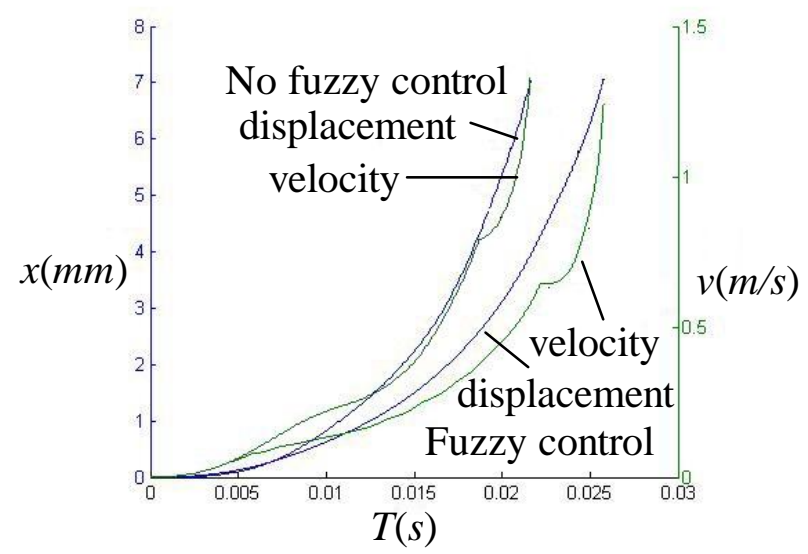

Figure 5. No fuzzy control and fuzzy conrol

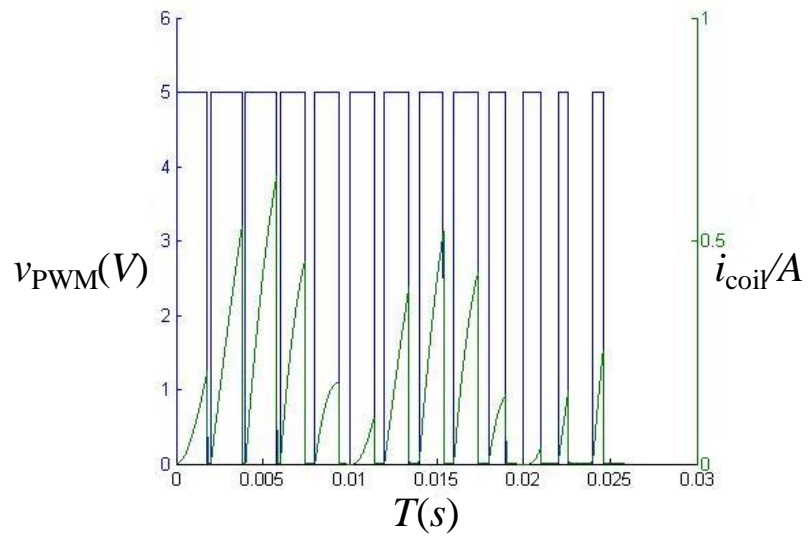

Figure 6. PWM and coil current

According to [11], it is known that reducing the collision between the cores is helpful to improve the electrical life of contactor. And the collision energy can be written as

$$
E=\frac{1}{2} \mathrm{~m} v^{2}
$$

According to the Eq. 2, when $\mathrm{m}$ is a fixed value, it is helpful to reduce the collision energy by reducing the final velocity of movable core, thus this method can improve the electrical life of PM contactor.

After the rectification of AC voltage, the angel of making process is range from $0^{\circ}$ to $180^{\circ}$. Six angels, namely, $0^{\circ}, 30^{\circ}, 60^{\circ}, 90^{\circ}, 120^{\circ}$, and $150^{\circ}$, are selected. The simulation results shows in Table 2 .

Table 2 Comparison between fuzzy control and no fuzzy control in the different phase angle

\begin{tabular}{ccccc}
\hline \multirow{2}{*}{ Angel of Making Process } & \multicolumn{2}{c}{$v_{\text {contact }}(\mathrm{m} / \mathrm{s})$} & \multicolumn{2}{c}{$v_{\text {core }}(\mathrm{m} / \mathrm{s})$} \\
\cline { 2 - 5 }$\varphi$ & Fuzzy & No Fuzzy & Fuzzy & No Fuzzy \\
\hline $0^{\circ}$ & 0.65 & 0.79 & 1.24 & 1.36 \\
$30^{\circ}$ & 0.65 & 0.78 & 1.24 & 1.36 \\
$60^{\circ}$ & 0.65 & 0.74 & 1.24 & 1.49 \\
$90^{\circ}$ & 0.65 & 0.72 & 1.24 & 1.60 \\
$120^{\circ}$ & 0.65 & 0.76 & 1.24 & 1.59 \\
$150^{\circ}$ & 0.65 & 0.79 & 1.24 & 1.40 \\
\hline
\end{tabular}


According to the Table 2, when fuzzy controller has not been applied to the PM contactor, the terminal speed of movable core $\left(v_{\text {core }}\right)$ is max in the $90^{\circ}$, and the max speed is $1.60 \mathrm{~m} / \mathrm{s}$. The terminal speed of movable contact $\left(v_{\text {contact }}\right)$ is max in the $0^{\circ}$ and $150^{\circ}$, and the max speed is $0.79 \mathrm{~m} / \mathrm{s}$. However when fuzzy controller is applied to the PM contactor, $v_{\text {core }}$ and $v_{\text {contact }}$ are the fixed values, $v_{\text {core }}$ is $0.65 \mathrm{~m} / \mathrm{s}, v_{\text {contact }}$ is $1.24 \mathrm{~m} / \mathrm{s}$. Thus fuzzy control can effectively reduce the influence of the phase angle on the dynamic characteristics of PM contactor. And fuzzy control can effectively reduce the $v_{\text {core }}$ and $v_{\text {contact }}$, at the same time, reducing the collision energy.

Within the range from $75 \%$ to $110 \%$ of the rated control voltage, PM contactor should achieve reliable work. Four voltages, namely, $180 \mathrm{~V}, 200 \mathrm{~V}, 220 \mathrm{~V}$, and $240 \mathrm{~V}$, are selected. The simulation is carried out, and the simulation results are shown in Table 3.

Table 3 Comparison between fuzzy control and no fuzzy control in the different control voltage

\begin{tabular}{ccccc}
\hline Control Voltage & \multicolumn{2}{c}{$v_{\text {contact }}(\mathrm{m} / \mathrm{s})$} & \multicolumn{2}{c}{$v_{\text {core }}(\mathrm{m} / \mathrm{s})$} \\
\cline { 2 - 5 }$U(\mathrm{~V})$ & Fuzzy & No fuzzy & Fuzzy & No Fuzzy \\
\hline 180 & 0.65 & 0.73 & 1.24 & 1.31 \\
200 & 0.65 & 0.76 & 1.24 & 1.34 \\
220 & 0.65 & 0.79 & 1.24 & 1.36 \\
240 & 0.65 & 0.81 & 1.25 & 1.42 \\
\hline
\end{tabular}

According to the Table 3, when fuzzy controller has not been applied to the PM contactor, the range of $v_{\text {contact }}$ is from $0.73 \mathrm{~m} / \mathrm{s}$ to $0.81 \mathrm{~m} / \mathrm{s}$, and the range of $v_{\text {core }}$ is from $1.31 \mathrm{~m} / \mathrm{s}$ to $1.42 \mathrm{~m} / \mathrm{s}$. However when fuzzy controller is applied to the PM contactor, $v_{\text {contact }}$ is the fixed value, $0.65 \mathrm{~m} / \mathrm{s}$. $v_{\text {core }}$ is about $1.24 \mathrm{~m} / \mathrm{s}$. Thus fuzzy control can effectively reduce the influence of the control voltage on the dynamic characteristics of PM contactor.

\section{Summary}

In the operating process of PM contactor, this paper puts forward a kind of PWM control method based on fuzzy control. The mechanical movement equation is built. And through the finite-element analysis, the electromagnetic force is obtained. Using MATLAB software designs the fuzzy controller and control system model of PM contactor. From the simulation results, it can be seen that this method can effectively reduce $v_{\text {core }}$ and $v_{\text {contact }}$, thus reduce the collision energy. Compared with the no fuzzy control, fuzzy control can availably reduce the influence of the operating phase angle and control voltage, so that it improves the stability of PM contactor.

\section{Acknowledgements}

Science and Technology Project of Minhang (No.: 2014MH134)

\section{References}

[1]X.B. Wang, H.Y. Lin, S.H. Fang, P. Jin and W.B. Mao: Low Voltage Apparatus, (2009) No. 7, p.4. (In Chinese)

[2] S.H. Fang, H.Y. Lin, B. Cai and X.J. Chen: Proceeding of the CSEE, Vol. 26 (2006) No.22, p.162. (In Chinese)

[3] H. Bak, J.S. Ro, T.K. Chung and H.K. Jung: IEEE Transactions on Magnetics, Vol. 49 (2013) No.11, p.5498.

[4] H.J. Bak, J.S. Ro, K.P. Yi, T.K. Chung and H.K. Jung: International conference on electrical machines and system (Busan, Korea, Oct. 26-29, 2013), p.676. 
[5] M.Z. Rong, P.G. Clem, J.Y. Low and X.H. Wang: Proceeding of the CSEE, Vol.25 (2005) No.1, p.109. (In Chinese)

[6] J.Y. Lou, M.Z. Rong, H.C. Zou, Z.B. Yuan aand X.M. Song: Proceeding of the CSEE, Vol. 24 (2004) No.4, p.120. (In Chinese)

[7] S.H. Fang, H.Y. Lin, B. Cai, X.J. Chen and X. Chen: Transaction of China Electrotechnical Society, Vol. 22 (2007) No.2, p.45. (In Chinese)

[8] Y. Kawase, T. Yamaguchi, K. Iwashita, T. Kobayashi and K. Suzuki: IEEE Transactions on Magnetics, Vol. 42 (2006) No.4, p.1339.

[9] H.Y. Lin, X.B. Wang, S.H. Fang, P. Jin and S.L. Ho: IEEE Transactions on Industrial Electronics, Vol. 60 (2013) No.11, p.5148.

[10] W.B. Mao, H.Y. Lin, X.B. Wang, S.H. Fang and P. Jin: Journal of Southeast University, Vol. 39 (2009) No.2, p.287. (In Chinese)

[11] X.B. Wang, H.Y. Lin, S.H. Fang, Q.W. Ren and P. Jin: Proceeding of the CSEE, Vol. 30 (2010) No.3, p.113. (In Chinese)

[12] X.B. Wang: Journal of System Simulation, Vol. 26 (2014) No.6, p.1331. (In Chinese)

[13] X.B. Wang, H.Y. Lin, S.H. Fang, Q.W. Ren and P. Jin: Proceeding of the CSEE, Vol. 31 (2011) No.18, p.93. (In Chinese)

[14] X.B. Wang, S.C. Ni, H.Y. Lin, S.H. Fang and P. Jin: Electric Machines and Control, Vol. 16 (2012) No.10, p.63. (In Chinese) 